\title{
Changes in the degree of bacterial contamination of different areas of a dental unit chair used in the clinical practice of dental hygiene after disinfection.
}

\author{
Ga-Young Lee, Sol Lee, Seul Lee, Ho-Ju Lim, Su-Bin Bang, Seoul-Hee Nam* \\ Department of Dental Hygiene, College of Health Sciences, Kangwon National University, Samcheok-si, Republic of \\ Korea
}

\begin{abstract}
This study was conducted to determine the importance of infection prevention and to promote effective disinfection through a comparison of the degrees of bacterial contamination before and after disinfection in the clinical laboratory of a dental hygiene department. The subjects were five infectionprone parts of a dental unit chair, including the back of the chair, the spitting bowl, the bracket button, the light handle, and the bracket handle, of the clinical laboratory of the dental hygiene department of $K$ University in Gangwon Province. To compare the degree of bacterial contamination before disinfection with that after disinfection, a sterilized cotton swab was used to swipe a $1 \times 1 \mathrm{~cm}$ area on the surface of a dental unit chair before disinfection, after which the cotton swab was promptly put into a sterilized saline solution. Safe Clean Spray (Associated Dental Products Ltd. Kemdent Works, Swindon, UK) was then applied to the same $1 \times 1 \mathrm{~cm}$ surface of the dental unit chair, and after $1 \mathrm{~min}$, another sterilized cotton swab was used to swipe the area, after which the cotton swab was promptly put into a sterilized saline solution. The bacteria on the cotton swab were smeared onto a Lysogeny broth (LB) agar medium and were cultured for $48 \mathrm{~h}$ at $37^{\circ} \mathrm{C}$. The colony-forming unit (CFU) results showed less bacteria after surface disinfection, and all the five areas of the dental unit chair showed significant results $(\mathbf{p}<0.05)$. The bacterial identification results showed the highest rate of enterococcus in the pre-disinfected spitting bowl, followed by the bracket handle, and the distribution of the gram-positive bacteria was high. Although most of the bacteria were eliminated after surface disinfection, there were some remaining bacteria. Therefore, the frequency of surface disinfection in clinical laboratories is increased to prevent human cross-contamination from bacteria, using a more potent and biostable disinfectant.
\end{abstract}

Keywords: Cross-infection, Surface disinfection, Bacterial contamination, Dental unit chair.

Accepted on November 8, 2018

\section{Introduction}

The dental hygiene department has been using an ultrasonic scaler on patients in the dental hygiene department clinical laboratory, for scaling practice. This creates an environment exposing both the patients and the dental practitioners to various types of pathogenic microorganism, and may become an important cause of disease [1]. In particular, the use of an ultrasonic scaler releases fine-droplet-shaped aerosols with infectious factors and toxic particles into the air [2]. The droplet-shaped aerosols float around in the air in the clinical laboratory and contaminate the bodies of the dental practitioner and patients as well as the surfaces of almost all the tools and equipment used in the clinic [3].

Cross-infection is the human-mediated infection of humans, such as the patients or their guardians and the hospital staff members, or the infection of humans mediated by materials like the diagnostic tools or equipment in the clinic [4]. It is very important as it causes infection of the patients and dental office staff during dental hygiene clinical practice through the aerosols in the air or the contaminated materials in the clinic, and plays the role of an infection pathway that can cause horizontal and vertical infection in other patients and their families [5]. The various microorganisms existing in the saliva or blood of the patients can cause indoor pollution and can become mediators for infection due to the various characteristics of dental practice. Therefore, infection management is very crucial [6].

Based on these characteristics of dental practice, the possibility of cross-infection from infectious microorganisms is very high in the dental staff and patients, and many endeavors have been made to prevent cross-infection. Exposure to patients with various lifestyles can cause repeated aerosol infection and can increase the possibility of cross-infection as well as the infection risk. Therefore, a practitioner can be a mediator at the center of multiple disease occurrence, and as such, thorough management is needed [7]. 
To prevent cross-infection, safety glasses, gloves, masks, and scrubs must be worn so these can block infectious materials like the saliva, blood, and aerosols from the patient's oral cavity [8]. Furthermore, hand washing is a primary preventive method for the cross-infection of practitioners from their patients as the hands are important factors in spreading infectious diseases [5]. Therefore, the use of a primary preventive method should be a priority in the prevention of cross-infection.

Additionally, all the tools and equipment used in dental procedures must be thoroughly sanitized and sterilized to prevent cross-infection and to minimize infection caused by direct/indirect contact with the patient's oral cavity [9]. Individual responsibility for infection prevention has not been properly practiced, however, and great and small risks existing widely in and around the clinical laboratories in schools can be easily overlooked and neglected. Aerosols including infectious factors and toxic substances float around in a restricted space and are then dropped and cause infection. Therefore, the surface of the dental unit chair must be frequently sanitized [10]. Kim et al. [11] stated that the contaminated surface of a dental unit chair can cause cross-infection of the patient, so it must be sanitized after the treatment of every patient. In a study investigating dental hygiene students' awareness of the risk of infection, a higher infection prevention practice rate was shown when there were concerns about exposure to infectious substances, blood, and saliva. The study emphasized the importance of infection prevention practice even after a simple procedure where one did not directly contact a contaminated substance, and the importance of the right recognition of infection prevention as well as the necessity of systemic education requiring active practice [12].

Therefore, this study investigated the degree of bacterial contamination and the types of bacteria present on the surface of a dental unit chair in the dental hygiene clinical laboratory of $\mathrm{K}$ University by comparing the degrees of bacterial contamination before and after disinfection. Furthermore, this study can be used to raise the awareness of the importance of infection prevention, and the study results can be used as primary data to promote effective disinfection.

\section{Materials and Methods}

Ten infection-prone unit chairs in the dental hygiene clinical laboratory of K University in Gangwon Province were selected for contamination evaluation. The surface bacteria on the back of the chair, the spitting bowl, the bracket button, the light handle, and the bracket handle were collected to investigate the degrees of bacterial contamination before and after sterilization. A sterilized cotton swab was used to swipe a $1 \times 1$ $\mathrm{cm}$ area of each of the five aforementioned parts of the dental unit chair before surface disinfection, after which the cotton swab was promptly put into a $1.5 \mathrm{ml}$ sterilized saline solution to determine the degree of surface bacterial contamination before surface disinfection. Safe Clean Spray (Associated Dental Products Ltd. kemdent Works, Swindon UK) listed in Table 1 was sprayed onto each of the same $1 \times 1 \mathrm{~cm}$ areas of the dental unit chair, and a sterilized cotton swab was used to swipe the area after 1 minute, after which the cotton swab was promptly put into a $1.5 \mathrm{ml}$ sterilized saline solution to determine the degree of surface bacterial contamination after disinfection. To identify the rate of bacterial growth, a $1 \mathrm{ml}$ smear preparation was made using Lysogeny broth (LB) agar, and it was cultured for $48 \mathrm{~h}$ at a $37^{\circ} \mathrm{C}$ culture medium. The colony-forming unit (CFU) of the LB agar plate was counted and recorded after the culture. Statistical analysis was then carried out using SPSS version 19.0 (SPSS Inc., Chicago, IL, USA). Student's t-test was conducted to identify the change from before to after disinfection. A p-value $<0.05$ was considered statistically significant. From each of the isolated and incubated microorganisms, genomic deoxyribo nucleic acid (DNA) was extracted and subjected to polymerase chain reaction (PCR), and sequencing was performed to identify the strain.

\section{Results}

\section{CFU changes before and after surface disinfection}

The degree of bacterial contamination of a dental unit chair in the clinical laboratory of $\mathrm{K}$ University before surface disinfection is shown in Figure 1. A large number of bacteria were shown at each of the five aforementioned parts of the dental unit chair prior to disinfection, and most of the bacteria were found to have been eliminated after surface disinfection. Table 2 presents the before- and after-disinfection CFU results. The degree of bacterial contamination was high prior to surface disinfection, and was highest in the spitting bowl (15.80 \pm 4.16 $\mathrm{CFU} / \mathrm{ml})$, followed by the bracket handle $(10.75 \pm 7.02 \mathrm{CFU} /$ $\mathrm{ml})$, the light handle $(7.17 \pm 2.22 \mathrm{CFU} / \mathrm{ml})$, the back of the chair $(6.38 \pm 2.88 \mathrm{CFU} / \mathrm{ml})$, and the bracket button $(10.75 \pm$ $7.02 \mathrm{CFU} / \mathrm{ml})$. All the five parts showed statistically significant decreases in bacteria after surface disinfection $(p<0.05)$.

\section{Surface bacteria analysis}

Table 3 shows the identification results of the bacteria that were purely separated from the surfaces of the five aforementioned parts of the dental unit chair. The grampositive bacteria exceeded the gram-negative ones in quantity, and Enterococcus faecalis, Staphylococcus warneri, Micrococcus luteus, and Bacillus licheniformis were identified. Among these, Staphlylococcus warneri were the most frequently identified, followed by Enterococcus faeclis. Furthermore, different types of bacteria were identified after the surface disinfection of the four parts of the dental unit chair other than the bracket handle, compared to before the surface disinfection, while identical bacteria were found on the bracket handle before and after surface disinfection. 
Changes in the degree of bacterial contamination of different areas of a dental unit chair used in the clinical practice of dental hygiene after disinfection

Table 1. Product used for the surface disinfection of the dental unit chair.

\begin{tabular}{ll}
\hline Product & Safe clean spray (Associated Dental Products Ltd. Kemdent Works, Swindon, UK) \\
\hline Application time & As per the manufacturer's directions, it was applied for 1 min for surface disinfection. \\
\hline Effective against & Gram-positive: Enterococcus faecalis, Micrococcus luteus, Staphylococcus warneri, Bacillus licheniformis \\
\hline Ingredients & Ethanol, didecylidimethylammonium chloride \\
\hline
\end{tabular}

Table 2. Bacterial contamination levels of the surfaces of the five parts of the dental unit chair before and after surface disinfection.

\begin{tabular}{llll}
\hline Group & & CFU (Mean \pm SD) & P-value \\
\hline Back of the chair & Before & $6.38 \pm 2.88$ & $0.020^{*}$ \\
\hline Back of a chair & After & $0.25 \pm 0.71$ & $0.020^{*}$ \\
\hline Spitting bowl & Before & $15.80 \pm 4.16$ & $0.016^{*}$ \\
\hline Spitting Bowl & After & $1.00 \pm 0.85$ & $0.016^{*}$ \\
\hline Bracket button & Before & $4.71 \pm 1.14$ & $0.000^{*}$ \\
\hline
\end{tabular}

\begin{tabular}{llll}
\hline Bracket Button & After & $0.60 \pm 0.54$ & $0.000^{*}$ \\
\hline Light handle & Before & $7.17 \pm 2.22$ & $0.015^{*}$ \\
\hline Light handle & After & $0.67 \pm 0.43$ & $0.015^{*}$ \\
\hline Bracket handle & Before & $10.75 \pm 7.02$ & $0.046^{*}$ \\
\hline Bracket handle & After & $0.38 \pm 0.37$ & $0.046^{*}$ \\
\hline
\end{tabular}

*Student's t-test; $p<0.05$

Table 3. Identification of the bacteria collected from the dental unit chair.

\begin{tabular}{|c|c|c|c|c|c|}
\hline Group & & Family & Species & Type & Primer sequence $\left(5^{`}-3^{`}\right)$ \\
\hline Back of the chair & Before & Enterococcaeceae & Enterococcus faecalis & Gram-positive & GGA TTA GAT ACC CTG GTA \\
\hline Back of the chair & After & Microcoaccaceae & Micrococcus luteus & Gram-positive & CCG TCA ATT CMT TTR AGT TT \\
\hline Spitting bowl & Before & Enterococcaeceae & Enterococcus faecalis & Gram-positive & GGA TTA GAT ACC CTG GTA \\
\hline Spitting bowl & After & Staphylococcaceae & Staphylococcus warneri & Gram-positive & GGA TTA GAT ACC CTG GTA \\
\hline Bracket button & Before & Staphylococcaceae & Staphylococcus warneri & Gram-positive & GGA TTA GAT ACC CTG GTA \\
\hline Bracket Button & After & Bacillaceae & Bacillus licheniformis & Gram-positive & GGA TTA GAT ACC CTG GTA \\
\hline Light handle & Before & Enterococcaeceae & Enterococcus faecalis & Gram-positive & GGA TTA GAT ACC CTG GTA \\
\hline Light handle & After & Staphylococcaceae & Staphylococcus warneri & Gram-positive & GGA TTA GAT ACC CTG GTA \\
\hline Bracket handle & Before & Staphylococcaceae & Staphylococcus warneri & Gram-positive & GGA TTA GAT ACC CTG GTA \\
\hline Bracket handle & After & Staphylococcaceae & Staphylococcus warneri & Gram-positive & GGA TTA GAT ACC CTG GTA \\
\hline
\end{tabular}

\section{Discussion}

Risks of cross-infection and nosocomial infection lie in clinical laboratories due to the aerosols from the patients' secretions (e.g., saliva, blood), the various pathogenic microorganisms, and the various dusts generated during clinical practice [13]. In addition, contacting various patients can increase the risk of acquiring an infectious disease and cross-contamination. Therefore, infection prevention efforts are important, and it is necessary to establish an infection prevention system [14]. Accordingly, dental hygiene students have an obligation to have an accurate knowledge of the situations that can cause cross-infection in the clinical laboratory, and to make an effort to prevent cross-infection within the laboratory by preventing such situations from arising.

Many pathogenic microorganisms can remain and survive on the surfaces of the tools and equipment in the dental clinic, which can cause infection. Yoon et al. [15] reported, however, that $74.5 \%$ of dental practitioners do not disinfect such surfaces after every treatment, and Bae et al. [16] reported that $72.1 \%$ do not do so. Moreover, both studies showed that surface disinfection is not being done properly. Furthermore, it has been reported that the bacterial contamination is very high when the surfaces of the tools and equipment in the dental clinic are not disinfected, and that pathogenic sources of infection can spread when a surface disinfectant is not used or when surface disinfection is not properly done [17]. Therefore, all the equipment and tools used during dental procedures, including the dental unit chair, require sterilization or disinfection, and thorough management is necessary [18].

To determine the extent to which the problem of the contamination of the equipment and tools in a dental clinic by microorganisms is addressed by surface disinfection, a bacterial contamination test must be conducted. Practical studies on bacterial contamination to determine the risk of surface contamination in clinical laboratories, however, are currently non-existent. Furthermore, as the risk of crossinfection has increased and the importance of infection 
management has emerged, data to be used as bases for the development of effective and practical infection management guidelines for dental hygiene students are necessary. Therefore, this study investigated the degree of bacterial contamination of the surface of a dental unit chair before and after surface disinfection by collecting bacteria from the dental unit chair of a clinical laboratory, and analysed the effects of surface disinfection on the degree of bacterial contamination.

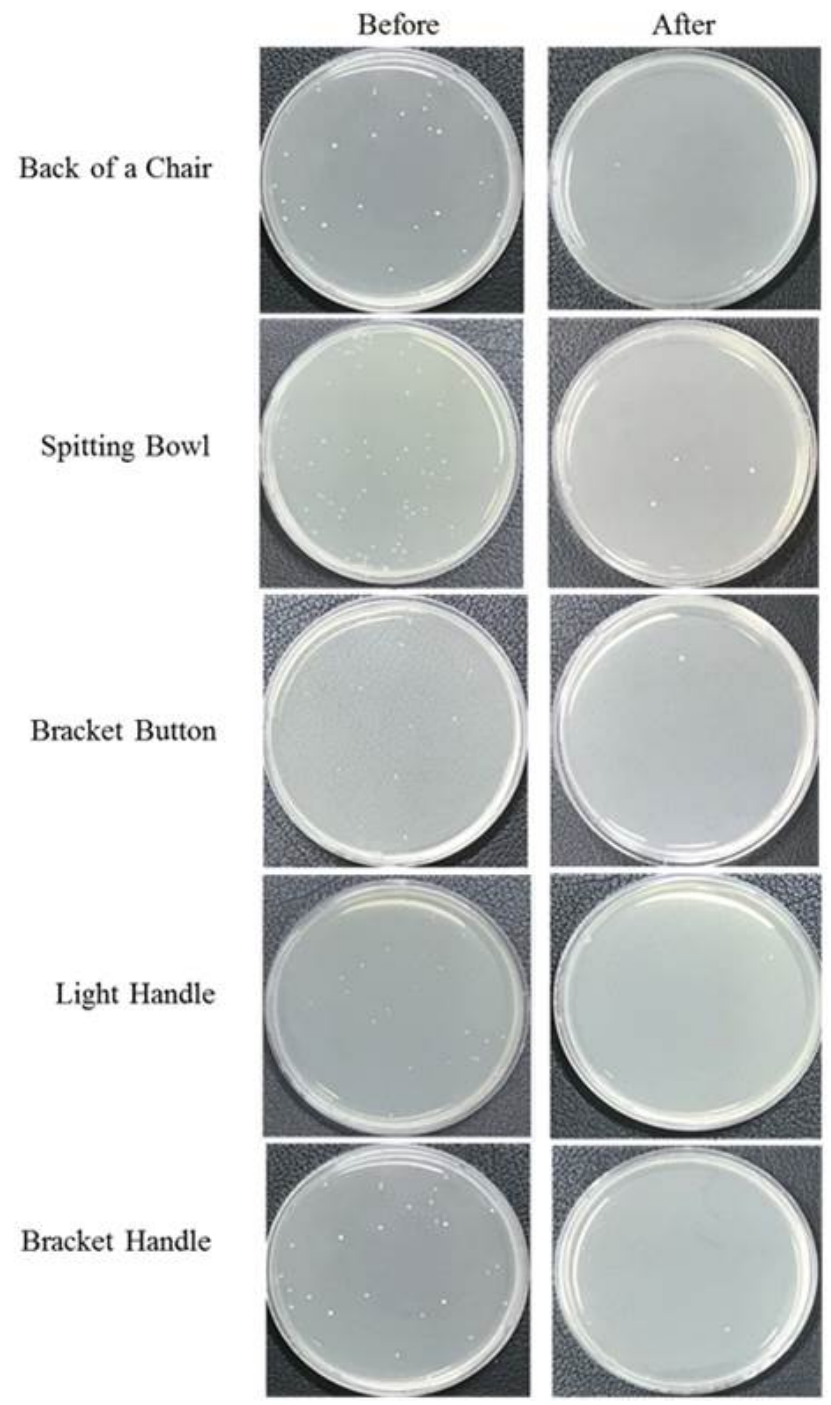

Figure 1. Changes in the number of surface microorganisms present in the five parts of the dental unit chair in this study from before to after disinfection.

As a result, when the degree of bacterial contamination before the surface disinfection of the dental unit chair at the clinical laboratory of the dental hygiene department of K University was compared to that after surface disinfection, the number of bacteria collected from the surfaces of the five aforementioned parts of the dental unit chair after disinfection was significantly lower $(\mathrm{p}<0.05)$. The CFU level on the spitting bowl prior to disinfection $(15.80 \pm 4.16 \mathrm{CFU} / \mathrm{ml})$ was highest among the five aforementioned parts of the dental unit chair, and was still higher $(1.00 \pm 0.85 \mathrm{CFU} / \mathrm{ml})$ than those of the four other parts of the dental unit chair after disinfection. This was consistent with the results of the study conducted by Park et al. [19], which showed the highest number of bacteria from the spitting bowl among the five surfaces. It is thus considered that the spitting bowl has a higher number of bacteria compared to the other parts of the dental unit chair due to the bacterial growth from secretions like the saliva and blood from the patient's oral cavity after a dental procedure. Therefore, it must be thoroughly disinfected among all the parts of the dental unit chair, and a more potent and biostable disinfectant must be used for this purpose to remove the remaining bacteria after surface disinfection. The result of the purely separated bacteria from the surface of the dental unit chair in the clinical laboratory in this study showed that gram-positive bacteria were distributed overall. After surface disinfection, Staphylococcus warneri was mostly detected from three parts: the spitting bowl, light handle, and bracket handle. Micrococcus luteus was detected from the back of the chair, and Bacillus licheniformis was detected from the bracket button. These results were consistent with those of a study on contamination in a dental clinic, which reported that Micrococcus uteus, Bacillus pumilus, and Staphylococcus aureus were detected from the back of the dental unit chair, the spitting bowl, and the light handle [20]. It has been reported that pathogens like Staphylococci and Streptococci were detected as indirect/direct infectious bacteria, causing serious problems like cross-infection [21]. In particular, Staphylococcus species was reported to have been detected in the air of a dental clinic when a high-speed dental drill was used with water spray, proving that the use of such drill with water spray causes infection during dental procedures [22]. Although Staphylococcus warneri, which was detected from the spitting bowl, light handle, and bracket handle in this study, rarely causes diseases in healthy adults, it has been reported that it can cause sepsis and osteomyelitis in immunosuppressed patients [23]. Micrococcus luteus, which was detected from the back of the chair in this study, exists in the nasal cavity, upper respiratory tract, and oral mucosa, and is known to cause meningitis and bacteremia when one is infected with it [24]. Bacillus is an aerobic gram-positive bacillus that forms spores. It exists anywhere in the surrounding environment and is frequently detected in dental clinics [25]. Severe infection from Bacillus licheniformis, which was detected in the bracket button in this study, is associated with immunosuppression and trauma, and it is known that antibiotic use easily treats the infected regions [26]. The microorganisms that were detected in this study suggest that the practice of thorough infection management is necessary due to the maximized risk of infection from these bacteria during various dental treatments. Based on these results, it is necessary to make dental hygiene students aware of the importance of surface disinfection in the clinical laboratory, and to increase the surface disinfection practice rate. In addition, review and application of the infection management factors in clinical laboratories affecting the numbers and types of bacteria, such as the disinfection method and frequency, are recommended to decrease the contamination rate by the surface bacteria. Therefore, it is considered that education of future dental hygienist for infection is necessary to encourage surface disinfection. 


\section{Conclusion}

Continuous measurement and analysis of the surface disinfection practice of clinical laboratories and the monitoring of effective infection management are considered necessary to minimize cross-infection and to protect dental hygiene students.

\section{Conflict of Interest}

The authors report no conflict of interest related to this study, and do not have any financial interest in the companies whose materials were included in this article.

\section{References}

1. Kim J, Woo HS, Jung MH. A study on the oral health status, PHP Index and oral health behavior of patients in $\mathrm{S}$ college dental clinic. J Dent Hyg Sci 2009; 9: 145-151.

2. Bentley CD, Burkhart NW, Crawford JJ. Evaluating spatter and aerosol contamination during dental procedures. J Am Dent Assoc 1994; 125: 579-584.

3. Crawford JJ, Broderius C. Control of cross-infection risks in the dental operatory: prevention of water retraction of bur cooling spray systems. J Am Dent Assoc 1988; 116: 685-687.

4. Shin SY, Yang YM, Kim MA, Kim JO, Baik BJ. The effectiveness of clinical sterilization methods in dental air/ water syringes. J Korean Acad Pediatr Dent 2013; 40: 268-273.

5. Leggat PA, Kedjarune U, Smith DR. Occupational health problems in modern dentistry: a review. Ind Health 2007; 45: 611-621.

6. Woo SH, Joo EJ. A study of personal protection equipment for infection control at dental offices. J Korean Soc Dent Hyg 2010; 10: 459-464.

7. Hardie J. Handpiece sterilization-the debate continues. J Can Dent Assoc 1993; 59: 355-362.

8. Lee JY, Jeong MK. A study on recognition and practice of dental hygiene students for infection control dental hygiene major courses. J Korean Acad Dent Edu 2009; 9: 73-88.

9. Ministry of Health and Welfare: Guideline on infection control in dental treatments. Ministry of Health and Welfare, Sejong, 2006; 1-3.

10. Anuradha P. Shikha S. Aerosols and oral health. Uni J Med Dent Sci 2015; 3: 11-13.

11. Kim KM, Hwang YS. A study on the state of infection control in dental clinic. J Korean Acad Dent Hyg Edu 2007; 7: 213-230.

12. Han OS, Lee JR. Study on awareness and degree of practice about infection control by dental hygienics students in some areas. J Dent Hyg Sci 2013; 13: 410-417.

13. Lee KH, Yang JE, Seon-Ho Mun SH, Kim JE. A study on the perception and needs about dental infection control of the dental patients. J Korean Soc Dent Hyg 2017; 17: 343-354.
14. Moon SE, Lee DD, Kwon HK, Kim KJ. Analysis of infection types on Stapylococcus aureus in dental office. J Korean Assoc Maxillofac Plast Reconsta Surg 2003; 25: 25-32.

15. Yun KO. A study on the influence factor to the bacterial contamination in the dental office. (unpublished doctoral dissertation). Asan Univ Soonchunhyang 2014; 1-2.

16. Bae MR. Cognition and performance on infection control of the clients and staffs in dental healthcare (Master's thesis). Kimhe University Inje 2011.

17. Jeong SY, Choi JH, Kim EK, Kim SM, Son HJ, Cho NH. Actual disinfection and sterilization control in Korean healthcare facilities. J Korean Acad Fundam Nurs 2014; 21: 392-400.

18. Choi JO, Lee YH, Nam SH. Factors affecting surface management of dental unit chair. Biomed Res 2018; 29: 3129-3134.

19. Park WY, Song CB, Lee SG, Lee KH. Relative light unit (RLU) count at the dental environment by use of FlugunTM and PCMX as a low temperature spray typed sterilization agent. Int J Clin Prev Dent 2012; 8: 165-171.

20. Yun KO, Kim HY. A study regarding bacterial contamination of surfaces in dental offices. Korean J Clin Lab Sci 2015; 47: 279-285.

21. Kugel G, Perry RD, Ferrari M, Lalicata P. Disinfection and communication practices: a survey of U.S. dental laboratories. J Am Dent Assoc 2000; 131: 786-792.

22. Mansour RA, Ali G, Mohammad RMN, Negar FN. Airborne microbial contamination of dental units. Tanaffos 2008, 7: 54-57.

23. Min JH, Park SN, Hwang HK, Min JB, Kim HS, Kook JK. Detection of methicillin or vancomycin-resistant Staphylococcus aureus from dental hospital. J Korean Acad Conserv Dent 2007; 32: 102-110.

24. Miltiadous G, Elisaf M. Native valve endocarditis due to Micrococcus luteus: a case report and review of the literature. J Med Case Rep 2011; 5: 251.

25. Kedjarune U, Kukiattrakoon B, Yapong B, Chowanadisai S, Leggat P. Bacterial aerosols in the dental clinic: effect of time, position and type of treatment. Int Dent J 2000; 50: 103-107.

26. Hong TW, Kim HY, Jee MG, Choi JW, Youg SJ, Shin KC, Lee WY. A case of bacillus licheniformis bacteremia associated with bronchoscopy. Tuberc Respir Dis 2004; 57: 553-556.

\section{*Correspondence to}

Seoul-Hee Nam

Department of Dental Hygiene

College of Health Sciences

Kangwon National University

Republic of Korea 